\title{
The Influence of Fitness Between Message Framing and Audience Regulatory Focus on Green Concern
}

\section{Advertisements Persuasion Effect}

\author{
Ya-Kang Chiu \\ Shih Hsin University, Taiwan \\ Wan-Ling Liu \\ Taiyi Advertising Corporation, Taiwan
}

\begin{abstract}
This study discusses the application of the regulatory focus of the individual motivation systems to green public service advertisements advocating environmental protection. First, it aims to determine whether the previously proposed regulatory fit theory can be applied to public service advertisements with characteristics different from those of commercial advertisements. Second, it aims to understand how to design messages to achieve the best effect on audiences with different foci. This study takes the regulatory focus theory as the basis and green public service advertisements as the films. After adopting $2 \times 2 \times 2$ three-factor design to test the interaction relations among the individual regulatory focus, message regulatory focus, and message framing. The results from the 217 college respondents indicate that the audience is influenced by regulatory focus when receiving messages from public service advertisements, which is similar to the influence of commercial advertisements. That is, when audience with a promotion focus, films with promotion focus and positive framing have a best advertisement effect. On the other hand, the audience with a prevention focus, films with prevention focus and negative framing also has a better advertisement effect.
\end{abstract}

Keywords: regulatory focus theory, motivation systems, regulatory fit, green concern

\section{Introduction}

Due to climate change, people all over the world have been suffering from abnormal climate in recent years. Typhoons and hurricanes, which have become stronger, have caused a large number of casualties and great economic loss. The continuous meltdown of ice layers and glaciers at the North and South Poles results in the enormous rise of the sea level. Island countries face the possibility of perishing. In addition, the unabated consumption of diminishing resources threatens the overall living environment. The warnings of nature and the shortage of resources have made all governments and private associations aware of the importance of

Ya-Kang Chiu, Assistant Professor, Department of Communications Management, Shih Hsin University.

Wan-Ling Liu, Project Manager, Taiyi Advertising Corporation.

Correspondence concerning this article should be addressed to Ya-Kang Chiu, No. 1 Lane 17 Sec.1, Mu-Cha Rd., Taipei, Taiwan. E-mail: kenchiu@cc.shu.edu.tw. 
environmental protection. The change has made environmental protection campaigns to be an important link in the social movements in recent years. Taiwan has started enacting regulations related to environmental protection, such as promoting special trash bags to reduce trash and to facilitate resource recovery. Treaties on environmental protection have been drafted between countries. The Kyoto Protocol was signed to regulate carbon dioxide emissions of all countries and to slow down the rate of global warming. The Copenhagen Climate Change Congress was held, wherein states discussed the solutions for climate change in the hopes of effectively preventing global crises. Aside from governmental initiatives, private associations have also taken action, such as creating and broadcasting advocacy advertisements and documentaries on environmental protection and energy conservation. These advertisements aim to inform the audience of the importance of environmental protection and to change their attitude toward issues related to environmental protection. Coupled with the framing of films and delivery of advertisement messages, these efforts are initiated to encourage audiences to start caring about the environment and contributing efforts toward environmental protection.

Affecting and changing the attitudes of consumers through the broadcasting of advertisement messages, which would make them purchase products or improve the brand image of the enterprise, is a widely used method by enterprises in marketing and promoting their products. Consumers receive various kinds of advertisement messages everyday, but not all of them produce the same persuasion effect. Different framings and presentation skills of advertisement messages influence the persuasion effect of messages on the consumers. To effectively utilize the budget spent on advertising, the characteristics that enable advertisement messages to attract consumers and to achieve the desired effects have become the focus of enterprise marketers. Consequently, these characteristics have become an important link in consumer behavior studies. Although significant achievements on the persuasion effect of advertisement messages have been realized in previous research, most studies focused on consumable commodity. Attitudes toward the products and purchase intentions of the respondents were measured after the designed messages were received. Previous research rarely took public service advocacy advertisement as the topic of the messages. The advertisement messages of consumable commodities deliver specific and explicit product information, whereas public service advocacy advertisements deliver a concept or an idea without any concrete entity, which causes difficulty in comprehension (Rothschild, 1979). Public service advocacy advertisements and commercial advertisements share the same objective of changing consumer attitudes and behaviors by using advertisement messages. However, public service advertisements aim at changing the intrinsic concepts and routine behaviors of the audience and affecting a wider area of daily living. This is in contrast with the commercial advertisements, which only aim to change consumer attitudes toward products or purchase intentions. In public service advertisements, the audience must consider more factors before making changes. Thus, the messages should have a better persuasion effect to better persuade the audience and to achieve the desired results.

Previous studies on the persuasion effect of messages show that the content delivered by messages should conform to the motivations and goals of the audience to enhance the persuasion effect of messages. Ultimately, the decision-making process and behaviors of audiences are affected. The regulatory focus theory proposed by Higgins (1997) explores individual motivations and goals and classifies the individual motivation system into two regulatory focuses: promotion focus and prevention focus. The type of regulatory focus has affects his/her 
motivations and goals. Scholars apply this theory to consumer motivation studies and advertisement message studies in the hopes of determining how to design messages consistent with the motivations and goals of individuals with different focuses, attract their attention, and achieve the desired persuasion effect (Aaker \& Lee, 2001).

Public service advertisements have different characteristics and audience focuses compared with commercial advertisements. This study focuses on green public service advertisements and intends to determine whether different message framings or characteristics of public service advertisements produce different persuasion effects on the audience in the same manner as the ordinary commercial advertisements. Therefore, the first research objective is aimed to exam whether the different message framings of public service advertisements produce different degree of persuasion effects on the audience?

The study also discusses the regulatory focus theory on the individual motivation systems to determine how to design the content and framing of the messages of public service advertisements. The second research objective is aimed at determine what type of message designing method should be adopted to achieve a better persuasion effect on audiences with different regulatory foci?

The paper is organized as follows: Section two deals with the literature review; Section three focuses on the research framework, hypotheses deployment, and research design; Section four shows the empirical results; Section five discusses the conclusion and managerial implications.

\section{Literature Review}

\section{Regulatory Focus Theory}

The mechanism of affecting decision-making process and behaviors through the individual intrinsic motivation has been the focus on motivations researches (Appelt \& Higgins, 2010; Florack, Frises, \& Scarabis, 2010). According to the earlier hedonic principle, behavioral tendencies, such as approach of pleasure and avoidance of pain are the major motivations that drive an individual to make decisions. However, when an individual makes a decision, considering both is often impossible, and thus the individual has to be inclined to either one. The person has to experience some pain if he/she chooses to pursue pleasure. For example, the person has to study hard to achieve the desired scores at the expense of his/her time for pleasure.

Higgins (1997) extended the hedonic principle, proposed the regulatory focus theory, and classified the individual motivation system into two regulatory foci: promotion focus and prevention focus. An individual is inclined to one of these two foci as the basis when a decision has to be made. The two foci are different from each other. An individual with promotion focus longs for desired pleasure (Yen, Yu, \& Chiu, 2009). Thus, the individual considers achievements, ideals, and ambitions as goals and values the existence of positive results. An individual with prevention focus hopes to avoid anticipated pain and thus considers duties and obligations as goals and values the existence of negative results (Higgins, 1997). Individuals with different regulatory focuses have different goals, cognitions, and assessments of matters, chosen behavior strategies and emotion treatment processes related to their goals (Faddegon, Ellemers, \& Scheepers, 2009).

Previous research points out that goals guide behaviors and individuals with different regulatory foci have different goals, which will guide them to adopt different behavior strategies to achieve their desired goals (Higgins, 2002; Friedman-Wheeler, Rizzo-Busack, Mclntosh, Ahrens, \& Haaga, 2010). An individual with 
strongly promotion focus adopts the strategy of eagerness and conducts behaviors that may be helpful for achieving the goals to ensure his/her desired goals can be achieved, and omissions can be prevented. An individual with prevention focus adopts the strategy of vigilance and becomes more cautious when choosing behaviors to avoid erroneous choices (Hamstra, Bolderdijk, \& Veldstra, 2010; Wang \& Lee, 2006). For example, contestants with different regulatory foci participate in an academic competition. The rule of the competition is that the one who gives the correct answer will receive the bonus, and the bonus of the one who gives the wrong answer will be deducted. In this case, a contestant with promotion focus actively answers questions, even if he/she is unsure of the answer, to gain more chances of acquiring the bonus. In contrast, a contestant with prevention focus only answers questions, he/she is definitely sure of preventing the earned bonus from being deducted because of an erroneous answer.

Generally, an individual possesses both regulatory foci as motivation systems. The individual choice one-sided in decision-making is affected by situation stimulation and the regulatory focus on the individual has been inclined to for a long time. With regard to the long-term inclination of regulatory focus, researchers have pointed out that individuals with promotion focus and those with prevention focus account for about half, respectively (Lee, Aaker, \& Gardner, 2000; Lockwood, Jordan, \& Kunda, 2002). Socialization in childhood, such as interaction with a caretaker, affects habitual inclination to one of the regulatory focuses. If the caretaker keeps encouraging a child to participate in activities and provides rewards, the child is likely to grow up to be an individual with promotion focus. If the caretaker often reminds a child of potential danger, the child grows up to be an individual with the tendency for prevention focus. Long-term regulatory focus can be measured by scales based on the respondent's answers (Higgins et al., 2001; Lockwood et al., 2002; Zacher \& de Lange, 2011). Situation stimulation or asking the respondent different questions can also make the respondent be inclined to one motivation system within a short time (Pham \& Avnet, 2004; Wang \& Lee, 2006).

Since the regulatory focus theory has been proposed, researchers have widely applied it to studying product marketing, classifying consumers based on this motivation system, understanding how regulatory focus guides consumer behaviors, and providing suggestions on marketing strategies. Louro, Pieters, and Zeelenberg (2005) pointed out that consumers with prevention focus do not decide to buy products immediately despite the positive experience provided. They think twice even if the experience with the product is positive. In terms of advertisement messages, individuals with prevention focus value not their own emotional response to the advertisement but the substantial messages delivered (Pham \& Avnet, 2004). These results help to understand the psychological states of individuals with different regulatory focuses, making them beneficial for marketing strategies and message designing.

\section{Regulatory Fit Theory}

After proposing the regulatory focus theory and applying it to discuss the characteristics of individuals with different motivation systems, Higgins et al. (2003) further developed it and proposed the regulatory fit theory. The theory proposes that regulatory fit is produced when the strategies adopted by an individual as the individual pursues goals in a specific situation or the characteristics of the activities that the individual participates in conform to the characteristics of his/her intrinsic regulatory focus (Plessner, Unkelbach, Memmert, Baltes, \& Kolb, 2009). Regulatory fit improves the strength of the motivation and enhances the 
original attitude of the individual toward a product or decision. Consequently, the individual either likes it more or hates it more (Aaker \& Lee, 2006; Memmert, Unkelbach, \& Ganns, 2010). Other than enhancing the attitude toward a certain product, regulatory fit also improves the evaluation of the product. An individual with a higher regulatory fit tends to give better evaluation to a chosen product and thus becomes willing to pay more (Avnet \& Higgins, 2006).

Regulatory fit enhances the strength of motivation, and the effect can be illustrated by two points (Aaker \& Lee, 2006). First, when an individual produces regulatory fit, the individual tends to have a feeling of it-just-feels-right for the chosen product, considers the decision right, improves confidence in the judgment, and gives the decision a high evaluation. Second, the feeling of it-just-feels-right is likely to cause a strong reaction from the individual to the situation or decision and increases participation strength.

According to previous research, two methods can be used to manipulate regulatory fit of individuals. Both process-based approach and outcome-based approach can produce an individual's regulatory fit (Aaker \& Lee, 2006). As mentioned, an individual's regulatory focus affects the thinking mode when making a decision. When making a decision, an individual with promotion focus is likely to be affected by the emotional response and judge in a perceptual way, whereas an individual with prevention focus tends to pay attention to the messages or statements in the situation and judge in a rational way. Therefore, making individuals with promotion focus consider the feeling that the product provides them and making individuals with prevention focus consider the functions of the product can produce the effect of regulatory fit and result in their high evaluation of the product (Pham \& Avnet, 2004).

In terms of manipulating the results of individual thinking, regulatory focus affects goals (Jin, 2010). Thus, individuals with promotion focus consider what benefits can be gained after decision-making, whereas individuals with prevention focus consider whether the decision will cause loss. Regulatory fit can then be achieved by making individuals with promotion focus consider the benefits they can gain by choosing a certain product or making individuals with prevention focus consider what they can lose if they do not choose a certain product (Higgins et al., 2003).

In changing the thinking mode of individuals, the different framings of messages (Lee \& Aaker, 2004) and the combination of individuals and message factors can affect regulatory fit and the strengthening of the evaluation of a product. However, researchers have found that the effect of regulatory fit is limited and not applicable to all situations. In some cases, an individual is aware of the fact that judgment and response are affected by regulatory effect. For example, when the thinking mode deviates from chronic focus, the individual may correct the deviation (Higgins et al., 2003), and may consider and evaluate more cautiously to avoid judgment deviation caused by the fit effect. In the research conducted by Wang and Lee (2006), the involvement degree of respondents is controlled to determine whether an individual's involvement degree affects the regulatory focus effect. Research results show that respondents with a high involvement degree spend the same effort and time in understanding both products whether fitness exists between product information and their own regulatory focus or not. In addition, their evaluation of the products is not affected by the effect of regulatory focus.

Regulatory fit is an important phenomenon. Researchers have tried to bridge consumer behavior and individuals' fundamental motivation with it (Aaker \& Lee, 2006). Research shows that the effect of regulatory 
fit improves the assessment of a product and enhances a product's value in the minds of the consumers. Such an effect can be further applied to the advertising strategies of an enterprise. According to similar research, the overall consumer market is divided almost equally into each of the two regulatory focuses. Therefore, when an enterprise designs its messages, the characteristics of individuals with regulatory focus should be considered, different framings should be employed, and product benefits of both pursuit of pleasure and avoidance of pain should be presented. Through this, all the consumers are covered and persuaded into buying the product. Effectiveness of the advertisement is thus achieved.

\section{Green Concern}

In the past few years, issues on green marketing have gradually developed from a borderline domain to a mainstream domain of consumer behaviors (Gardner \& Abraham, 2010). As a result, more consumers hope that the overall environment will become better. More importantly, governments and consumers have started to change their purchasing behaviors (Palmujoki, Parikka-Alhola, \& Ekroos, 2010; Davis, 1993). To adapt to such change in the consumers, enterprises have begun to promote green products and have established the strategy of green marketing. Marketers are trying to develop a strategy capable of locking the marketing target on consumers with green concern (McDaniel \& Rylander, 1993). Consequently, marketing has become an issue requiring tremendous attention to understand the components of consumers' green concern and the relationship between green concern and green purchasing behaviors.

When studying green concern, scholars classify the concept into four components for measurement and discussion: ecological knowledge; ecological affect; ecological intention; and ecological behavior (Maloney \& Ward, 1973). Previous research shows that the former three components are positively correlated with an individual's ecological behavior.

In terms of relevant knowledge, Simmons and Widmar (1990) proposed that an individual's lack of ecological knowledge was a great barrier toward undertaking resource recovery. Research also shows that an individual's ecological knowledge and ecological behavior are positively correlated (Stern, 1992; Gruner, 1993). As regards the individual's ecological effect, many previous studies show that it can be used to effectively predict an individual's ecological behavior due to the positive correlation between them (Dispoto, 1997; Li, 1997). Moreover, research reveals that ecological intention is positively correlated with ecological behavior (Chan \& Yam, 1995; Li, 1997). Such a relationship conforms to the theory of reasoned action proposed by Ajzen and Fishbein (1973) who believed that intention was a necessary process before behavior and can be used to predict actual behaviors.

An individual's higher green concern results in more willingness to conduct green behaviors and to pay more attention to green products (Coddington, 1993). Therefore, green concern is an important factor in an individual's decision whether to conduct green behaviors and accept green products. An enterprise should master the characteristics of consumers with a higher green concern before setting marketing strategies to achieve better effects.

\section{Research Methodology}

\section{Research Framework}

The research framework is shown is Figure 1. This study takes the regulatory focus theory as the basis and 
green public service advertisements as the respondent of films. It is focused on whether interactions of individual regulatory focus (promotion focus vs. prevention focus), message regulatory focus (pursuing acquisition vs. avoiding loss), and message framing (positive framing vs. negative framing) have significant influences on advertisement effects. Effects are classified into three: individuals' attitude toward the film; persuasion effect of the film on individuals; and behavioral intentions. In addition, as the films used in this research feature environmental protection, individual green concern is added to the research framework as the control variable to avoid the influence of individuals' green concern on the effect of the independent variable on individuals.

\begin{tabular}{|l|l|l|}
\hline Individual regulatory focus & & \multicolumn{2}{|c|}{ Advertisement effect } \\
$\cdot$ & Attitude \\
$\cdot \quad$ Promotion focus & Persuasion effect \\
$\cdot \quad$ Prevention focus & Intentions \\
Message regulatory focus & & \\
$\cdot \quad$ Pursuing acquisition & \\
$\cdot \quad$ Avoiding loss & \\
Message framing & Positive framing & \\
$\cdot \quad$ Negative framing & Green concern \\
\hline
\end{tabular}

Figure 1. Research Framework.

\section{Hypotheses Deployment}

According to research on the regulatory fit theory, the effect of regulatory fit improves an individual's evaluation of a product and enhances attitude toward the product. That is, the individual either likes it more or hates it more. Lee and Aaker (2004) found that fitness between message regulatory focus and framing also affected the evaluation of products by an individual. If the message regulatory focus is pursuing acquisition, the emphasis of framing lies in whether the individual can gain positive results. This finding is consistent with the fact that positive message framing stress on compliance with the message can bring about positive results. Therefore, regulatory fit is supposed to be achieved for films with the message regulatory focus of pursuing acquisition and positive framing.

Based on previous research, respondents with promotion focus hold positive attitude toward the films with a higher fitness between the message regulatory focus of pursuing acquisition and positive framing when the variable of individual regulatory focus is added. The films produce a better persuasion effect and higher intention on respondents. On the contrary, respondents with prevention focus develop a higher fitness for films with the message regulatory focus of avoiding loss and negative framing. Therefore, the following hypotheses are proposed.

H1: For the chronic promotion focus respondents, film with the message regulatory focus of pursuing acquisition and positive framing produces better advertisement effect than the other three groups of films.

H1a: For the chronic promotion focus respondents, film with the message regulatory focus of pursuing acquisition and positive framing have higher attitude toward films than the other three groups.

H1b: For the chronic promotion focus respondents, film with the message regulatory focus of pursuing acquisition and positive framing produces better persuasion effect than the other three groups.

H1c: For the chronic promotion focus respondents, film with the message regulatory focus of pursuing 
acquisition and positive framing produces higher behavioral intentions than the other three groups.

H2: For the chronic prevention focus respondents, film with the message regulatory focus of avoiding loss and negative framing produces better advertisement effect than the other three groups of films.

H2a: For the chronic prevention focus respondents, film with the message regulatory focus of avoiding loss and negative framing have higher attitude toward films than the other three groups.

H2b: For the chronic prevention focus respondents, film with the message regulatory focus of avoiding loss and negative framing produces better persuasion effect than the other three groups.

H2c: For the chronic prevention focus respondents, film with the message regulatory focus of avoiding loss and negative framing produces higher behavioral intentions than the other three groups.

\section{Experimental Design}

This study adopts a $2 \times 2 \times 2$ three-factor design to study the interaction relations among the three variables. As to experiment design, the two variables of message regulatory focus and framing are combined, and the four groups of experimental films are produced and presented with pictures, music, and voiceover narration. Each film lasts for about two minutes. Each group of films is played for respondents with promotion focus and prevention focus. Questionnaires are distributed to all the respondents. The questions deal with their attitude toward the films to measure the persuasion effect and influence of the films on the intention of the respondents after watching.

A total of 217 college students were recruited. They were shown four groups of randomly-distributed experimental films to prevent the content and framing of films from affecting their regulatory focus and green concern. Each group was asked to fill up the scales measuring the individual regulatory focus and green concern before watching the films. The scale measuring regulatory focus proposed previously by Lockwood et al. (2002) was adopted, which was proven to have excellent reliability and validity. A total of 18 questions were asked. Nine questions measured individual promotion focus, and the other nine measured prevention focus. The respondent were also asked to answer the questions according to the seven-point scale (ranging from strongly agree to strongly disagree). As to the scale measuring green concern, 16 questions were formed by revising the questions on ecological intention and ecological behavior based on the scale proposed by Maloney, Ward, and Braucht (1975).

After the respondents completed the two-scale questionnaires, they were shown the experimental films and were then asked to complete another questionnaire related to the films. The questionnaire was composed of four parts with 11 questions. The first question was designed as the manipulation check of the positive and negative framing of the films. The respondents were asked if the film was positive or negative, with the answers ranging from 1 (negative) to 7 (positive). In the other three parts, four questions were asked about the respondent's attitude toward the film, three were about the persuasion effect of the film, and three were on the respondent's intention after watching the film.

\section{Results}

\section{Data Analysis}

The questionnaire showed considerable reliability. The individual regulatory focus scale, green concern scale, respondents' attitude toward the films, persuasion effect of the films, and respondents' intentions all 
reach 0.7 .

According to the results of the ANOVA, interaction between the three factors has a significant influence on the three dependent variables of this study: respondents' attitude toward the film ( $\left.\mathrm{F}_{\text {attitude }}=4.19, p<0.01\right)$, persuasion effect of the film ( $\left.\mathrm{F}_{\text {persuasion effect }}=2.234, p<0.05\right)$, and respondents' intention ( $\mathrm{F}_{\text {intention }}=10.793, p$ $<0.01$ ). This finding indicates that interaction among the three variables of individual regulatory focus, message regulatory focus, and message framing have the significant influence on the advertisement effect.

Since the interaction among the three variables produce a significant influence on the advertisement effect, this study hopes to further understand how the combination of message regulatory focus and framing should be designed to produce better advertisement effects on individuals with promotion focus or prevention focus. Therefore, when analyzing of variances with planned contrast, respondents with promotion focus and prevention focus should be divided into different groups before the process of comparing the four groups of films.

First, the attitudes of respondents with promotion focus on the four groups of films are compared and the results are shown in Figure 2. The results indicate that the respondents have higher attitudes toward the group of films with pursuing acquisition and positive framing $\left(\mathrm{M}_{\text {attitude }}=4.616\right)$ than toward films with pursuing acquisition and negative framing ( $\mathrm{M}_{\text {attitude }}=3.693, p<0.01$ ) and those with loss avoidance and positive framing ( $\left.\mathrm{M}_{\text {attitude }}=3.83, p<0.01\right)$. The comparison between attitudes toward films with acquisition pursuing and positive framing and those with loss avoidance and negative framing loss ( $\left.\mathrm{M}_{\text {attitude }}=4.285, p=0.07\right)$ has a high mean value but the difference does not reach significant level.

The result shows that the respondents' attitude toward films with acquisition pursuing and positive framing is only significantly higher than that toward the two groups of films, thus Hypothesis H1a is not supported. Respondents' attitude toward films with pursuing acquisition and positive framing as well as the attitude toward those with avoiding loss and negative framing are not significantly different. However, the mean score is higher than their attitude toward films with avoiding loss and negative framing. This follows the same direction of difference as that of H1a. Thus, H1a is partly supported. A possible reason for the insignificant difference between the attitude toward films with pursuing acquisition and positive framing and the attitude toward those with avoidance of loss and negative framing is that this study adopts scales to measure individual regulatory focus. This results in the insignificant difference between respondents at the borderline of people with promotion focus and prevention focus. Some respondents classified as having promotion focus may possess certain characteristics of prevention focus. In addition, they hold high attitude toward films with avoidance of loss and negative framing, although the difference is insignificant from their attitude toward films with pursuing acquisition and positive framing.

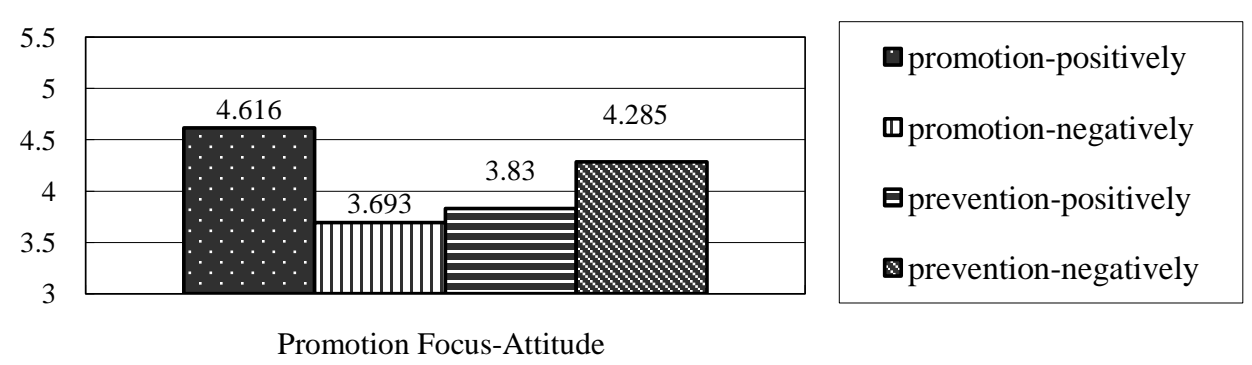

Figure 2. Mean score of respondents' attitudes with promotion focus. 
The comparative results of the persuasion effects among the four groups of films on respondents with promotion focus are shown in Figure 3. The result indicates that films with pursuing acquisition and positive framing have a higher persuasion effect $\left(\mathrm{M}_{\text {persuasion effect }}=4.8\right)$ on the respondents than that of the other three groups of films with pursuing acquisition and negative framing $\left(\mathrm{M}_{\text {persuasion effect }}=4.303, p<0.05\right)$, films with avoidance of loss and positive framing $\left(\mathrm{M}_{\text {persuasion effect }}=4.537, p<0.01\right)$, and films with avoidance of loss and negative framing ( $\mathrm{M}_{\text {persuasion effect }}=4.761, p<0.05$ ). The analysis supports $\mathrm{H} 1 \mathrm{~b}$ and indicates that the persuasion effect of films with pursuing acquisition and positive framing on respondents with promotion focus is higher than that of the other three groups of films.

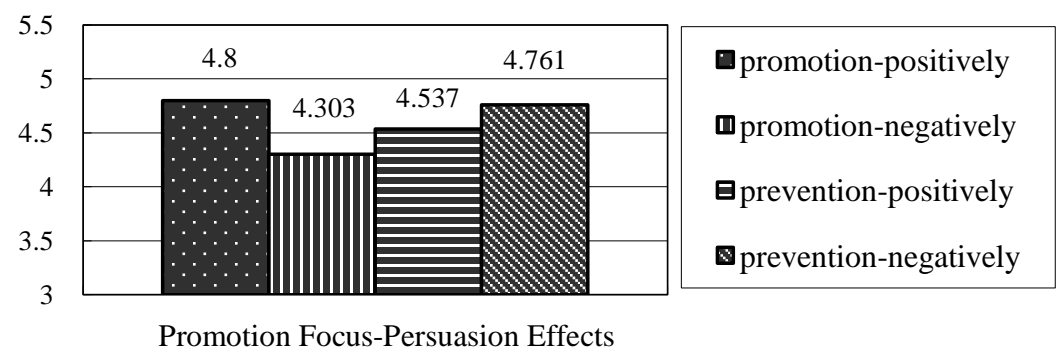

Figure 3. Mean score of respondents’ persuasion effects with promotion focus.

Finally, the comparative results of respondents after watching the four groups of films are shown in Figure 4 that the intention of respondents with promotion focus after watching films with pursuing acquisition and positive framing $\left(\mathrm{M}_{\text {intention }}=5.244\right)$ is significantly higher than the results of respondents watching the other groups of films, namely, films with pursuing acquisition and positive framing ( $\mathrm{M}_{\text {intention }}=3.757, p<0.01$ ), films with avoidance of loss and positive framing $\left(\mathrm{M}_{\text {intention }}=4.225, p<0.01\right)$, and films with avoidance of loss and negative framing $\left(\mathrm{M}_{\text {intention }}=4.773, p<0.01\right)$. The result supports H1c and indicates that the intention of respondents with promotion focus produced after watching films with pursuing acquisition and positive framing is higher than that produced after watching the other three groups of films.

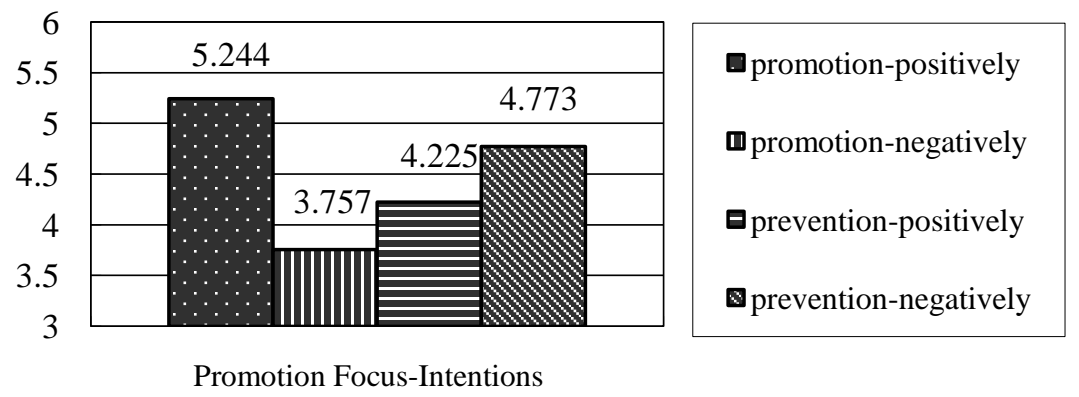

Figure 4. Mean score of respondent' intentions with promotion focus.

The analysis on the attitudes of respondents with prevention focus toward the four groups of films indicates that the attitude of respondents toward films with avoidance of loss and negative framing $\left(\mathrm{M}_{\text {attitude }}=\right.$ 4.788) is higher than that toward films with pursuing acquisition and positive framing ( $\mathrm{M}_{\text {attitude }}=3.973, p<$ $0.05)$ and films with avoidance of loss and positive framing ( $\left.\mathrm{M}_{\text {attitude }}=4.115, p<0.05\right)$. However, compared with the attitude toward films with pursuing acquisition and negative framing ( $\left.\mathrm{M}_{\text {attitude }}=4.093, p=0.7\right)$, the 
difference is not reach significant level. Thus, H2a is not supported. Although the attitude of the respondents toward films with avoidance of loss and negative framing and the attitude toward films with pursuing acquisition and negative framing are not significantly different from each other, the mean score of the attitude of the respondents toward films with avoidance of loss and negative framing is higher, with the same direction of difference as that in H2a, which is partly supported.

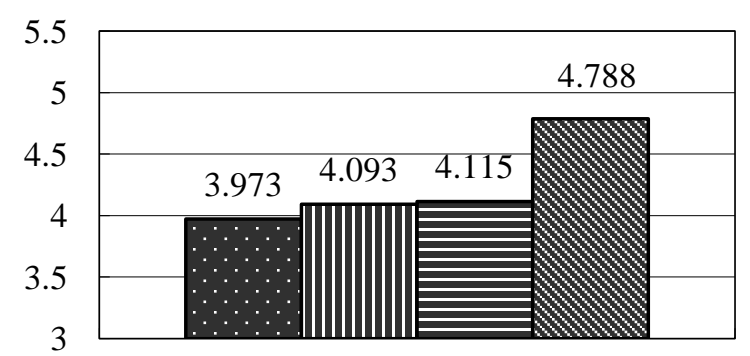

$$
\begin{aligned}
& \text { •promotion-positively } \\
& \text { 凹promotion-negatively } \\
& \text { घprevention-positively } \\
& \text { \$prevention-negatively }
\end{aligned}
$$

Prevention Focus- Attitude

Figure 5. Mean score of respondent' attitudes with prevention focus.

The analysis results of the persuasion effects of four groups of films on respondents with prevention focus are shown in Figure 6. The result indicates that the persuasion effect of films with avoidance of loss and negative framing on respondents ( $\left.\mathrm{M}_{\text {persuasion effect }}=5.038\right)$ is not significantly different from that of any of the other three groups. Thus, H2b is not supported. The possible reason for the insignificant difference is that the persuasion effect of films may be partly influenced by the attitude toward the films or relevant topics. In addition, knowledge gained from inquiry outside of the process may result in some deviations. However, by comparing the mean score of the groups, the mean score of the persuasion effect of films with avoidance of loss and positive framing is higher than that of films with pursuing acquisition and positive framing $\left(\mathrm{M}_{\text {persuasion effect }}=\right.$ 4.571, $p=0.18)$, films with pursuing acquisition and negative framing ( $\mathrm{M}_{\text {persuasion effect }}=4.5, p=0.21$ ), and films with avoidance of loss and positive framing $\left(\mathrm{M}_{\text {persuasion effect }}=4.551, p=0.23\right)$. The direction of difference is the same as that in $\mathrm{H} 2 \mathrm{~b}$.
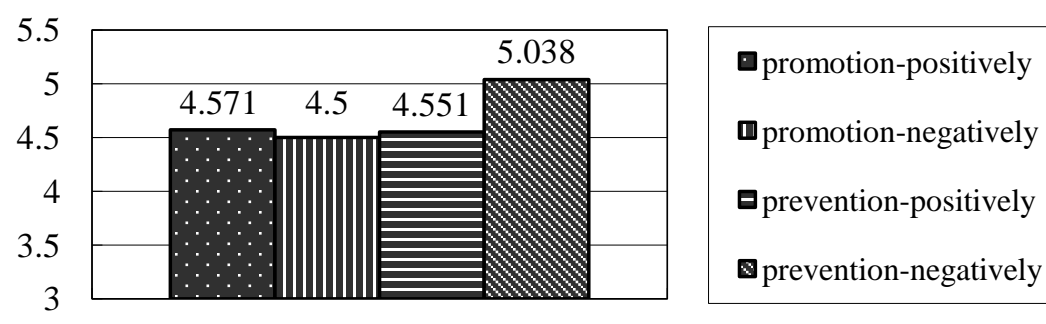

Prevention Focus- Persuasion Effect

Figure 6. Mean score of respondent’ persuasion effects with prevention focus.

The comparative results on the intentions of respondents after watching the four groups of films are shown in Figure 7. The result indicates that the intention after watching films $\left(M_{\text {intention }}=5.064\right)$ with avoidance of loss and negative framing is higher than that for films with pursuing acquisition and positive framing $\left(\mathrm{M}_{\text {intention }}=\right.$ 4.25, $p<0.01)$, films with pursuing acquisition and negative framing $\left(\mathrm{M}_{\text {intention }}=4, p<0.01\right)$, and films with avoidance of loss and positive framing $\left(\mathrm{M}_{\text {intention }}=3.576, p<0.01\right)$. Therefore, the results support H2c and 
indicate that watching films with avoidance of loss and negative framing causes the higher intention of respondents with promotion focus than that of the three other groups of films.

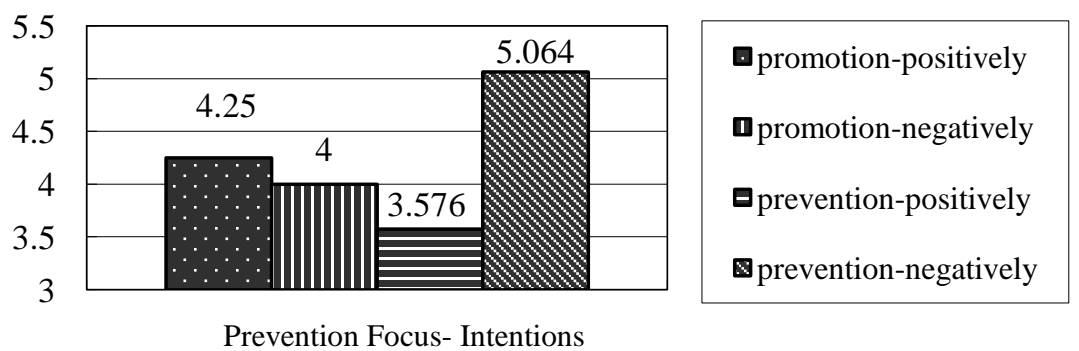

Figure 7. Mean score of respondent' intentions with prevention focus.

The comparative results and analysis of different groups indicate that the persuasion effect and intention of films with pursuing acquisition and positive framing on respondents with promotion focus are higher than those of the three other groups. Thus, H1b and H1c are supported. The attitude of the respondents toward the films with pursuing acquisition and positive framing is higher than that toward the other two groups of films. This result is insignificantly different from those in films with avoidance of loss and negative framing. However, by comparing the mean score of attitudes of the groups, the mean score of the attitude toward films with pursuing acquisition and positive framing is higher than that toward films with avoidance of loss and negative framing. The direction of difference is the same as that of H1a, and thus the hypothesis is partly supported.

The analysis results of the respondents with prevention focus indicate that only the intentions of respondents after watching films with avoidance of loss and negative framing are higher than those of the other three groups. Therefore, H2c is supported. The mean score of attitude and persuasion effect of the respondents toward films with avoidance of loss and negative framing are higher than those of the other three groups, but the differences are not significant. Thus, H2a is partly supported and H2b is not supported.

\section{Conclusions}

The experimental films of this research were edited and incorporated with pictures and voiceover narration. The films were significantly different from advertisements with moving pictures and storylines. Therefore, the films may have produced stimuli that are not as strong as those of actual advertisements, although some advertisements do not have an obvious effect on the audience.

Environmental protection has become an urgent issue in the society. Both the green public service advocacy advertisements of environmental protection associations and the green marketing strategies adopted by enterprises are related to environmental protection. Advertisements and films on environmental protection are continuously produced, but only few studies have been made on the persuasion effect of public service advertisements. Therefore, this study focuses on environmental protection and applies the regulatory focus theory, which is proven valuable in discussing individual motivations in the study of advertisement effects.

Data analysis indicates that the interaction among individual regulatory focus, message regulatory focus, and message framing have a significant influence on advertisement effects. The study further discusses how the designed messages should be combined to produce better fitness for individuals with promotion focus and prevention focus to improve the advertisement effect. Research results show that films with the message 
regulatory focus of pursuing acquisition and positive framing have better fitness with individuals with promotion focus than the other three groups of films, whereas films with the message regulatory focus of avoidance of loss and negative framing have better fitness with individuals with prevention focus than the other three groups of films. Additionally, films produce better advertisement effect when fitness exists between individuals and films. Therefore, the effect of regulatory fit will not be hindered by the difference between public service advertisements and commercial advertisements. Fitness or unfitness is caused by the interaction between message framing and individual regulatory focus, further affecting the advertisement effects.

Message framing, whether in commercial advertisements or public service advertisements with significantly different characteristics, interacts with individual characteristics and then affects advertisement effect. Most public service advertisements merely employ the message framing of emotional appeal to arouse the audience's empathy, making them contribute money or change their behaviors and concepts. Aside from moving the audience with emotional appeal, the results suggest that message framing consistent with individual regulatory focus can be designed or content consistent with the desired state of individual regulatory focus can be arranged to produce better advertisement effects.

\section{References}

Aaker, J. L., \& Lee, A. Y. (2001, June). I seek pleasures and we avoid pains: The role of self regulatory goals in information processing of persuasion. Journal of Consumer Research, 28, 33-49.

Aaker, J. L., \& Lee, A. Y. (2006, February). Understanding regulatory fit. Journal of Marketing Research, 43, 15-19.

Appelt, K. C., \& Higgins, E. T. (2010, November). My way: How strategic preferences vary by negotiator role and regulatory focus. Journal of Experimental Social Psychology, 46, 1138-1142.

Avnet, T., \& Higgins, E. T. (2006). How regulatory fit affects value in consumer choices and opinions. Journal of Marketing Research, 43(1), 1-10.

Coddington, W. (1993). Environmental marketing: Positive strategies for reaching the green consumer. New York: McGrew-Hill.

Davis, J. J. (1993). Strategies for environmental advertising. Journal of Consumer Marketing, 10(2), 19-36.

Dispoto, R. G. (1997). Interrelationships among measures of environmental activity, emotionality and knowledge. Educational and Psychological Measurement, 37(summer), 451-459.

Faddegon, K., Ellemer, N., \& Scheepers, D. (2009). Eager to be the best, or Vigilant not to be the worst: The emergence of regulatory focus in disjunctive and conjunctive group tasks. Group Processes and Inter-group Relations, 12(5), 653-671.

Florack, A., Frises, M., \& Scarabis, M. (2010). Regulatory focus and reliance on implicit preferences in consumption contexts. Journal of Consumer Psychology, 20(2), 193-204.

Friedman-Wheeler, D. G., Rizzo-Busack, H., Mclntosh, E., Ahrens, A. H., \& Haaga, D. A. (2010). Manipulating regulatory focus in cigarette smokers. Addictive Behaviors, 35(5), 530-532.

Gardner, B., \& Abraham, C. (2010). Going green? Modeling the impact of environmental concerns and perceptions of transportation alternatives on decisions to drive. Journal of Applied Social Psychology, 40(4), 831-849.

Hamstra, M. R. W., Bolderdijk, J. W., \& Veldstra, J. V. (2010). Everyday risk taking as a function of regulatory focus. Journal of Research in Personality, 45(1), 134-137.

Higgins, E. T. (1997). Beyond pleasure and pain. American Psychologist, 52(12), 1280-1300.

Higgins, E. T. (2002). How self-regulation creates distinct values: The case of promotion and prevention decision making. Journal of Consumer Psychology, 12(3), 177-191.

Higgins, E. T., Idson, L. C., Freitas, A. L., Spiegel, S., \& Molden, D. C. (2003, June). Transfer of value from fit. Journal of Personality and Social Psychology, 84, 1140-1153.

Higgins, E. T., Friedman, R. S., Harlow, R. E., Idson, L. C., Ayduk, O. Z., \& Taylor, A. (2001). Achievement orientations from subjective histories of success: Promotion pride versus prevention pride. European Journal of Social Psychology, 31(1), 3-23.

Jin, S. A. (2010). I can be happy even when I lose the game: The influence of chronic regulatory focus and primed self-construal on exergamers' mood. CyberPsychology, Behavior \& Social Networking, 13(4), 467-471. 
Lee, A. Y., \& Aaker, J. L. (2004). Bringing the frame into focus: The influence of regulatory fit on processing fluency and persuasion. Journal of Personality and Social Psychology, 82(2), 205-218.

Lee, A. Y., Aaker, J. L., \& Gardner, W. (2000, June). The pleasures and pains of distinct self-construals: The role of interdependence in regulatory focus. Journal of Personality and Social Psychology, 78, 1122-1134.

Li, L. Y. (1997). Effect of collectivist orientation and ecological attitude on actual environmental commitment: The moderating role of consumer demographics and product involvement. Journal of International Consumer Marketing, 9(4), 31-53.

Lin, C. H., \& Huang, C. W. (2011). The effects of regulartory focus and bundle-pricing framing on consumers' preceptions of loss. Social Behavior \& Personality: An International Journal, 39(1), 113-117.

Lockwood, P., Jordon, C. H., \& Kunda, Z. (2002). Motivation by positive or negative role models: Regulatory focus determines who will best inspire us. Journal of Personality and Social Psychology, 83(4), 854-864.

Louro, M. J. S., Pieters, R., \& Zeelenberg, M. (2005). Negative returns on positive emotions: The influence of pride and self-regulatory goals on repurchase decisions. Journal of Consumer Research, 31(4), 833-840.

Maloney, M. P., \& Ward, M. P. (1973, July). Ecology: Let's hear from the people: An objective scale for the measurement of ecological attitudes and knowledge. American Psychologist, 28, 583-586.

Maloney, M. P., Ward, M. P., \& Braucht, G. N. (1975, July). A revised scale for the measurement of ecological attitudes and knowledge. American Psychologist, 30, 787-792.

McDaniel, S. W., \& Rylander, D. H. (1993). Strategic green marketing. Journal of Consumer Marketing, 10(3), 4-10.

Memmert, D., Unkelbach, C., \& Ganns, S. (2010). The impact of regulatory fit on performance in an inattentional blindness paradigm. Journal of General Psychology, 137(2), 129-139.

Palmujoki, A., Parikka-Alhola, K., \& Ekroos, A. (2010). Green public procurement: Analysis on the use of environmental criteria in contracts. Review of European Community \& International Environmental Law, 19(2), 250-262.

Pham, M. T., \& Avnet, T. (2004, March). Ideals and oughts and the reliance on affect versus substance in persuasion. Journal of Consumer Research, 30, 503-518.

Plessner, H., Unkelbach, C., Memmert, D., Baltes, A., \& Kolb, A. (2009). Regulatory fit as a determinant of sport performance: How to succeed in a soccer penalty-shooting. Psychology of Sport \& Exercise, 10(1), 108-115.

Rothschild, M. L. (1979, Spring). Marketing communications in nonbusiness situations or why it's so hard to sell brotherhood like soap. Journal of Marketing, 43, 11-20.

Simmons, D., \& Widmar, R. (1990). Motivations and barriers to recycling: Toward a strategy for public education. Journal of Environmental Education, 22, 13-18.

Stern, P. (1992, October). What psychology knows about energy conservation. American Psychologist, 47, 1224-1232.

Wang, J., \& Lee, A. Y. (2006, February). The role of regulatory focus in preference construction. Journal of Marketing Research, 43, 28-38.

Yen, C. L., Yu, C. W., \& Chiu, F. C. (2009). The influence of regulatory fit on persuasion under different military operations: The moderating effects of need for cognition. Military Psychology, 21(3), 396-411.

Zacher, H., \& de Lange, A. H. (2011). Relations between chronic regulatory focus and future time perspective: Results of a cross-lagged structural equation model. Personality \& Individual Differences, 50(8), 1255-1260. 